\title{
Pragmatismo y semiótica de Pierce en la organización de la información
}

\author{
Pragmatismo e Semiótica de Peirce na organização da informação \\ Pragmatism and Semiotics of Peirce in the organization of information
}

Carlos Cândido de ALMEIDA

Universidade Estadual Paulista - UNESP, Brasil, Marília - São Paulo, Av. Higyno Muzzi Filho, 737, CEP: 17525-900, carlosalmeida@marilia.unesp.br

\begin{abstract}
Resumen
La Semiótica, así como su raíz teórica, el Pragmatismo, están asociados a la figura del lógico y filósofo estadounidense Charles Sanders Peirce (1839-1914). Entre Pragmatismo y Semiótica hay un vínculo embrionario, y no se debe descuidar tal conexión cuando se reflexiona sobre las contribuciones teóricas a la Ciencia de la Información, específicamente, a la organización de la información. Se exponen, inicialmente, la relación entre Pragmatismo y Semiótica de C. S. Peirce. Posteriormente, se analizan también dos contribuciones de Peirce, ambas fundamentales para comprender algunos aspectos de la organización de la información y del conocimiento.
\end{abstract}

Palabras clave: Semiótica. Pragmatismo. Organización de la información. Peirce, Charles Sanders. Organización del conocimiento.

\section{Notas iniciais}

É lugar-comum na Ciência da Informação a tentativa de esquivar-se de teorias que não têm uma aplicabilidade imediata. A hipótese defendida por muitos é que as demandas sociais devem dirigir a busca de conceitos e teorias, e tão logo elas são identificadas, devem ser inseridas nos sistemas de informação e documentação. No entanto, uma ciência não poderia ser considerada uma empresa, seus propósitos passam também por descobrir e explicar; a aplicação é uma variação necessária da utilidade de seu conhecimento. Quando pensamos em uma ciência, cujo objeto seja a informação, em suas várias dimensões sociais, acreditamos que ela deve, antes de produzir resultados, explicar racionalmente os fenômenos, sob pena de sua atividade cientifica ser comparada ao simples registro de sucessos e insucessos das experiências.

Então, devemos considerar os esforços que vão na direção das matrizes teóricas de um campo científico, mesmo que a aplicação ou a utilidade não seja muito nítida. Supõe-se que é justamente essa quantidade de propostas explicativas e opções teóricas que permite grandes fusões

\begin{abstract}
Semiotics, as well as its theoretical root, Pragmatism, are associated with the figure of the logical and the American philosopher Charles Sanders Peirce (18391914). Between Pragmatism and Semiotics, there is an embryonic link, and this connection should not be ignored when reflecting on their theoretical contributions the Information Science and, specifically, to knowledge organization. Initially, the relationship between Pragmatism and Semiotics of C. S. Peirce is explored. Subsequently, two contributions of Peirce, both fundamental to understand some aspects of the organization of information and knowledge, are carefully discussed.
\end{abstract}

Keywords: Semiotics. Pragmatism. Organization of information. Knowledge organization. Peirce, Charles Sanders.

conceituais e a constituição de teorias na fronteira disciplinar. A linguagem é um exemplo de objeto que surge na esteira das ligações entre diversos campos científicos, e a sua compreensão é cada vez mais requisitada socialmente.

Na primeira década do século XXI as sociedades humanas deparam-se com uma exposição violenta a mensagens de toda sorte. Seja devido aos recursos tecnológicos de processamento de dados - os quais convertem texto, imagem e som em uma mesma estrutura binária -, ou pela valorização social do conhecimento, identificamos uma necessidade sem precedentes de nos comunicar. Percebemos, mesmo em países em desenvolvimento, a patente utilidade da educação formal e de programas de educação continuada. Nesse contexto, também crescem as dúvidas quanto à capacidade humana de processar mensagens e se comunicá-las eficazmente. Como o homem lê o mundo e como a realidade torna-se inteligível à cognição são indagações legítimas e carecem de contribuições teóricas.

A cognição e a comunicação da informação podem ser consideradas processos de natureza 
semiótica, sendo de interesse da Ciência da Informação conhecê-los. Presumimos que a Semiótica, a ciência geral dos signos, entrou em contato com a Ciência da Informação recentemente, porém as raízes desta aproximação podem não estar muito claras, especialmente, quando não se propõe estudar sua vinculação teórica com a Filosofia.

Tanto a Semiótica quanto a sua raiz teórica - o Pragmatismo - estão associadas à figura do lógico e filósofo estadunidense Charles Sanders Peirce (1839-1914). É evidente que outras matrizes semióticas seriam de grande utilidade à Ciência da Informação, tal como as propostas semiológicas de Roland Barthes, ou mesmo de Algildas Greimas. Contudo, a Semiótica de Peirce convida-nos a pensar a respeito da natureza da relação signo e mundo, e como esse processo semiótico promove a cognição.

Entre Pragmatismo e Semiótica existe um vínculo embrionário, e não podemos desconsiderar tal conexão quando refletimos sobre as contribuições à Ciência da Informação, notadamente, a organização da informação. Iniciarei a exposição relacionando Pragmatismo e Semiótica de C. S. Peirce. Posteriormente, listarei duas contribuições do Pragmatismo e da Semiótica de Peirce, fundamentais para compreender aspectos da organização da informação e do conhecimento. Ressalta-se que esta breve comunicação trata do relato de resultados de investigação realizada anteriormente (Almeida, 2009).

\section{Pragmatismo e Semiótica de Peirce}

Muitos escritos peirceanos são úteis para entrar em seu Pragmatismo (Questões sobre certas faculdades reivindicadas pelo homem, 1866; Algumas consequências de quatro incapacidades, 1868; A fixação das crenças, 1877; Como tornar claras nossas ideias, 1878; Conferências sobre Pragmatismo, 1903; O que é o pragmatismo, 1905, dentre outros). Comentadores da obra de Peirce, entre os quais Santaella (2004, p. 26), sustentam que o Pragmatismo peirceano pode ser dividido em dois grandes períodos: o primeiro momento refere-se à máxima pragmatista, e no segundo procura-se fundamentar um método de determinação de conceitos intelectuais, recorrendo-se na seleção de hipóteses. Nesse último, o Pragmatismo sugere o afastamento de "filosofias de faz-de-conta" e concentrar os esforços intelectuais em problemas reais.

A primeira fase do Pragmatismo, expressa na máxima de 1878, busca verificar os significados dos pensamentos, somando os efeitos práticos concebíveis e resultantes da ação deste pensamento. Assim: "Considerar que efeitos - ima- ginavelmente possíveis de alcance prático concebemos que possa ter o objeto de nossa concepção. A concepção desses efeitos corresponderá ao todo da concepção que tenhamos do objeto." (Peirce, 1972, p. 59, CP 5.402). Tal regra guia o pensamento no sentido de descobrir como deixar as ideias claras e distingui-las das obscuras. O Pragmatismo é um método cuja adoção garantirá a clareza do pensamento. Para tanto, o pensamento deve obedecer a uma regra para obter ideias realmente claras.

A máxima pragmatista de 1878 foi reavaliada pelo próprio Peirce, por volta de 1905, como relata em uma carta endereçada a Mario Calderoni, em que reconheceu que tal postura era ultra-pragmatista (Silveira, 1985, p. 6). Nessa fase ainda, destaca-se as conferências de Peirce sobre o Pragmatismo, oportunidade em que o autor reata diversos pontos de sua obra, aparentemente dispersos e desconectados. Um destes foi o conceito de crença apontado nos anos de 1870 .

Para que uma ideia seja aceita, ela precisa tomar a forma de uma crença. Por crença entende-se o processo pelo qual a mente concretiza um hábito, controle ou regras de ação. A crença pode ser quebrada ou desfeita quando uma mente se irrita com uma indagação real que, possivelmente, proporcionará o limiar de um novo hábito.

Salienta-se que o significado no Pragmatismo não está condicionado ao conceito estabelecido e consolidado no passado, contudo, é regido pelas ações futuras. Significar é sempre estar aberto à futura significação. Em outras palavras, atribuir significado é crer na influência da previsão do comportamento dos fenômenos.

Em síntese, o Pragmatismo de Peirce é um instrumento ou - mais precisamente - um método para auxiliar a Filosofia, dentre outras ciências, a clarificar os fundamentos de seus argumentos e tornar as idéias distintas e passíveis de experimentação. É um método de reflexão, no sentido de servir para analisar as concepções cotadas para aceitação.

Ibri (1992, p. 102), Silveira (2007, p. 182) e De Waal (2007, p. 40) não hesitam em afirmar que o Pragmatismo de Peirce é um método para determinar o significado. De longe, o pragmatismo peirceano afasta-se do entendimento vulgar que relaciona a palavra "pragmatismo" às ações que repercutem algum resultado (ou benefício) prático.

Quando o Pragmatismo sugere um caminho para atingir as crenças, recorre aos tipos de inferência, os quais são signos complexos, pois 
não se pode pensar sem signos, conforme sustenta Peirce. A ciência geral dos signos de Peirce fundamenta-se nas categorias fenomenológicas, e não podemos conceituar signo sem fazer referência às categorias da experiência, a saber: primeiridade, secundidade e terceiridade.

$\mathrm{Na}$ primeiridade são encontradas ideias relacionadas ao acaso, diversidade, qualidade, multiplicidade, possibilidade, incerteza, caos, entre outras. A segunda categoria compreende o que Peirce considera por experiência, válida para todos os tipos de fenômenos em experiências diretas. É na secundidade que se encontram ideias de ação e reação, neste caso, uma experiência só pode acontecer na medida em que existir uma dualidade. A terceira categoria reúne as duas últimas numa síntese. A terceiridade pode também ser tomada como sendo mediação, em que se encontram ideias de generalização dos fenômenos, lei, regularidade; chegando ao nível da razão e constituindo o pensamento em signos. O signo, na visão peirciana, não é estanque nem tampouco se reduz a um produto da mente humana. Signo é de caráter geral, correspondendo a tudo o que se possa imaginar ou observar. Santaella (2000) discute os malentendidos encontrados na literatura que reduzem a ideia de signo ao signo mental.

\section{Signo para Peirce (1972, p. 143)}

[...] é um objeto que, de uma parte, está em relação com seu objeto e, de outra parte, com um interpretante, de maneira tal a colocar o interpretante para com o objeto numa relação que corresponde à sua própria relação com o objeto.

O signo, no relacionamento com o objeto, faz surgir signos icônicos, indiciais e simbólicos. Essa conexão existente entre estas duas entidades é tênue, no sentido em que o signo, genericamente, só pode ser afetado pelo objeto imediato, que é um objeto como representado pelo signo, destro deste mesmo signo. O objeto imediato é a primeira parte das duas existentes para a divisão do objeto. A segunda parte do objeto é o objeto dinâmico; é o objeto como ele é, reagindo sobre outros existentes. Seria o objeto real (na realidade direta de secundidade) independente de uma mente interpretadora, considerando, por exemplo, a mente humana. $\mathrm{O}$ signo em relação a ele mesmo faz surgir os tipos de signos conhecidos por qualissignos, sinsignos e legissignos. Ademais, o signo em relação ao interpretante propõe os tipos rema, dicente e argumento.

O interpretante ou hábito de ação leva uma mente a se comportar de um estado definido. Uma visão ampla do interpretante é aquela que o coloca como representação originada num acaso absoluto - comum da primeira categoria de fenômeno -, passando pelo choque encontrado no nível dos existentes (secundidade). Com vistas ao emprego mais específico da definição de interpretante, é incluída a noção de interpretante de um pensamento humano executado por um intérprete. $O$ interpretante é um terceiro, o signo ou mais restritamente o representamen, é um primeiro e o objeto que determina os dois anteriores, direta ou indiretamente, é um segundo.

O interpretante é a imagem, o sentido ou o conceito referente ao objeto que denota; ele não apenas representa o objeto, tal como o signo faz em primeiridade, mas fornece uma ideia geral a respeito do objeto. Isso não significa que o interpretante seja diferente do signo, ele mesmo é um signo de outro signo e permanecerá na base para outros signos subsequentes. $O$ interpretante é o conceito que significa e representa o signo pertencente à terceira categoria $e$ recebe também uma divisão tripartida: Interpretante imediato, Interpretante dinâmico e Interpretante final. Como as definições das divisões dos interpretantes são várias, recomendamos para uma visão aprofundada do assunto a consulta a outras obras (Santaella, 2000; Coelho, 1999).

\section{Semiótica e Organização da Informação e do Conhecimento}

Organização da informação, no contexto da Ciência da Informação, é um núcleo de pesquisa. O pressuposto assegura que para disseminar informação deve-se, em primeiro lugar, organizálas sob as mais diferentes formas. Com isso, uma das preocupações da organização da informação é estudar os processos, os produtos e os instrumentos que melhor viabilizam a estruturação de informação, para posterior recuperação.

O conhecimento para a organização do conhecimento é, sobretudo, um produto social. Hjorland $(2003$, p. $87-88$ ) argumenta que para a comunidade da Ciência da Informação a organização do conhecimento significa organização da informação em registros bibliográficos, devendo respeitar a melhor maneira de construir os registros e utilizá-los via recuperação da informação. A seguir, apresentarei duas contribuições do Pragmatismo e Semiótica de Peirce à organização da informação e do conhecimento.

\subsection{Processo semiótico de indexação}

Com o objetivo de encontrar os fundamentos dos processos da organização da informação, aportamos na Semiótica peirceana, em especial, nas classes de signos. O processo de inde- 
xação realiza-se mediante etapas bem delineadas, não obstante, os signos criados pelo indexador no momento de indexar um documento recebem pouca atenção.

Nesse sentido, os principais trabalhos sobre a questão são de autoria de Mai (1997a, 1997b, 1999, 2000), o qual sustenta que o processo de indexação de assunto pode tomar como base a Semiótica peirceana. O argumento central do autor é considerar que os processos envolvidos na indexação de assunto estão permeados de interpretações (Mai, 2001, p. 591). A premissa remonta ao pensamento peirceano sobre a natureza própria do signo, isto é, a de gerar no processo de evolução, sucessivas interpretações. Vale-se de dois conceitos fundamentais da semiótica: a semiose ilimitada e as classes de signos.

Mai (1997b, p. 64) sustenta que todos os quatro elementos do processo geral de indexação (documento, assunto, descrição formal do assunto e entrada de assunto) são signos e as etapas da indexação fazem a conexão entre eles, configurando-se no pivô da semiose, ação dos signos. Para aceitar concretamente a semiose como um conceito indispensável para explicar o fenômeno da indexação, tal como procedeu o autor, exige-se, em primeiro lugar, a adoção do conceito triádico de signo. Em outras palavras, o objeto do signo, juntamente com o representamen e o interpretante, estão intrinsecamente ligados. Em segundo lugar, a proposta da semiose já antecipa que o final do processo nunca cessa, mas apenas há ocasiões em que o signo estabiliza-se. Isso explicaria as razões pelas quais, depois de passar por todas as etapas de análise e tradução, os termos de um documento não conseguem assegurar a univocidade na interpretação empreendida pelo usuário. Às vezes, nem mesmo assegura que outro profissional dotado da mesma competência e experiência reproduza a mesma interpretação.

Para Mai (2001), o documento, primeira representação em contato com o indexador, é em si mesmo um signo do tipo Argumento, na medida em que representa um conjunto de ideias e conhecimento supondo um conjunto de convenções dispostas em um contexto social e cultural para se realizar. A natureza do assunto, tal como argumenta Mai (2001, p. 615), é de um Símbolo Dicente cujo representamen é um legissigno, em sua relação com o objeto é um símbolo, ambos na terceiridade. Uma descrição do assunto, terceiro elemento do processo de indexação de assunto, se comportará como um Legissigno Indicial Dicente. A descrição do assunto, tendo a forma de um legissigno, refere-se ao assunto ou aos assuntos, e chama a atenção para ele, trazendo algum tipo de informação concreta sobre o objeto, isto é, que nele deve conter elementos característicos de um determinado assunto. O quarto elemento é o produto da série de etapas anteriores, entrada de assunto, a qual se apresenta de uma maneira difícil de definir em termos unilaterais. A entrada de assunto é categorizada como um Legissigno Indicial Remático.

Em suma, Mai utiliza da Semiótica as classes de signos de Peirce, as quais não podem ser compreendidas sem a menção ao Pragmatismo.

\subsection{Organização Semiótica do Conhecimento}

A proposta teórica mais abrangente entre as examinadas foi desenvolvida pelo autor dinamarquês Torkild Leo Thellefsen. A contribuição fundamental de seus estudos é resgatar temas pouco examinados da obra peirceana pela organização da informação e do conhecimento, tais como: Terminologia e Pragmatismo de Peirce, e utilizá-los para compor uma teoria para a área. A perspectiva adotada privilegia a abordagem filosófica de Peirce, não se restringindo à análise da Semiótica enquanto Gramática Especulativa (que identifica os tipos e classes de signos).

De fato, a contribuição de Thellefsen enquadrase em um nível mais elevado da interação com a Filosofia e Semiótica peirceanas. Entre os vários estudos do autor, vale ressaltar os trabaIhos em que desenvolve (Thellefsen, 2002, 2003, 2004, Thellefsen; Thellefsen, 2004) especificamente, a teoria da organização semiótica do conhecimento.

Em termos semióticos, os conceitos de um domínio de conhecimento são considerados signos do tipo simbólico na perspectiva semiótica, pois são regidos pela convenção que estabelece que um conjunto de ideias se associa a um objeto. Nesse sentido, um símbolo supõe uma relação interpretativa com os objetos, a fim de gerar hábitos. Thellefsen (2002, p. 79) argumenta que a formação de hábitos nasce porque as pessoas, em um dado domínio do conhecimento, partilham metas comuns. A evolução dos conceitos em um contexto cultural para Thellefsen supõe a criação e a quebra de hábitos.

A origem do domínio também recebe uma interpretação semiótica. De uma vaga e aleatória hipótese (primeiridade), uma ideia relaciona-se a ideias semelhantes (secundidade). Dessa associação surge uma regularidade nas ideias consideradas semelhantes que representam um conjunto de fenômenos a serem interpretados 
de uma determinada forma. Essa regularidade conduz a uma tendência formadora de hábitos (terceiridade); assim, um conceito de um tal domínio do conhecimento é aceito definitivamente. Nesse sentido, um conceito científico, cuja natureza é de um símbolo, evolui até constituir-se em um signo fundamental, base estrutural para qualquer domínio de conhecimento, nas palavras de Thellefsen $(2002,2003)$.

Com efeito, a organização semiótica do conhecimento é, sobretudo, uma teoria que fundamenta a organização do conhecimento dos domínios. Ampara-se na Filosofia e na Semiótica de Peirce para criar os conceitos de signo fundamental e efeito-significância (ou seja, o efeito de significado), ambos aplicados aos domínios do conhecimento.

\section{Questões em aberto}

A despeito de ser comum entre os comentadores de Peirce o estudo do Pragmatismo, não parece ser objeto de interesse geral na organização da informação e do conhecimento. É possível que esse fato tenha provocado atrasos à formulação de explicações adequadas ao contexto dos sistemas de informação e documentação. O Pragmatismo é um grande esforço de operacionalizar, entre outras coisas, a terminologia da ciência, responsável por representar a comunicação entre os cientistas. Ora, o desenvolvimento ótimo de um sistema de informação e documentação requer o conhecimento das formas de produção do significado no contexto das comunidades científica. Peirce acreditava que com uma boa terminologia haveria segurança na produção de novos conhecimentos, tratando, assim, de associar a definição de conceitos e termos ao método pragmatista e à Semiótica.

A relevância do Pragmatismo e da Semiótica de Peirce não se mede apenas pela definição da análise documental de conteúdo como ato de tradução no espectro de quaisquer sistemas de informação. Portanto, devemos considerar como temas em discussão e de potencial interesse à organização da informação os seguintes: abdução (como inferência que melhor responde ao propósito de criar ideias novas que se constituirão em hábito interpretativo que guia uma mente na obtenção de um conhecimento seguro, disponível para uma possível ativação em uma situação futura) e hábito (o qual determina as condições da cognição; sendo assim, o profissional indexador está submetido a forças reais que delimitam as disposições das interpretações futuras). Desvendar o conteúdo dos hábitos é um processo indispensável para conhecermos as variáveis associadas ao processo de interpretação do especialista responsável pela análise documental de conteúdo em sistemas de informação e documentação. Desse modo, é preciso assumir a Semiótica de Peirce como Lógica (Pura e Retórica Especulativa) e estudar a inferência abdutiva - enquanto processo e etapa inicial da análise documental - bem como os fundamentos do Pragmatismo de Peirce para a organização da informação e do conhecimento.

Por fim, ressaltamos que nem todas as possibilidades teóricas dirigidas à organização da informação e do conhecimento configuram-se como recortes conceituais aplicáveis e produtivos, às vezes, uma sugestão teórica serve unicamente para ampliar nossos horizontes sobre os objetos estudados e as práticas que realizamos.

\section{Referencias}

Almeida, C. C. (2009). Peirce e a organização da informação: contribuições teóricas da Semiótica e do Pragmatismo. Marília: Programa de Pós-Graduação em Ciência da Informação, Universidade Estadual Paulista, 2009. Tese de doutorado.

De Waal, C. (2007). Sobre pragmatismo. São Paulo: Loyola, 2007.

Hjørland, B. (2003). Fundamentals of knowledge organization. // Knowledge Organization. 30: 2 (2003) 87-111.

Ibri, I. A. (1992). Kósmos noetós: a arquitetura metafísica de Charles S. Peirce. São Paulo: Perspectiva; Hólon, 1992.

Mai, J-E (1997b). The concept of subject: on problems in indexing. // Mcllwaine, I. C. (ed.). Knowledge organization for information retrieval: 6th International Study Conference on Classification Research. The Hague: FID, 1997. 60-67. (FID, n. 716).

Mai, J-E (2001). Semiotics and indexing: an analysis of the subject indexing process. // Journal of Documentation. 57: 5 (September 2001) 591-522.

Mai, J-E. (1997a). The concept of subject in a semiotic light. // Schwarts, C.; Rorvig, M. (ed.). Digital collections: implications for users, funders, developers and maintainers. Medford, NJ: Information Today, 1997. 54-64. (Proceedings of the ASIS Annual Meeting; 34)

Mai, J-E. (2000). The subject indexing process: an investigation of problems in knowledge representation. Austin: Faculty of Graduate School of Library and Information Science, The University of Texas, 2000. Doctorate Thesis.

Peirce, C. S. (1931-1958). Collected Papers of Charles Sanders Peirce. Cambridge, MA: Harvard University Press, 1931-1958. 8 v. (re-impressão de Thoemmes Press, 1998).

Peirce, C. S. (1980). Escritos coligidos. São Paulo: Abril Cultural, 1980

Peirce, C. S. (1972). Semiótica e filosofia. São Paulo: Cultrix, 1972

Peirce, C. S. (2000). Semiótica. São Paulo: Perspectiva, 2000.

Santaella, L. (2000). A teoria geral dos signos: como as linguagens significam as coisas. São Paulo: Pioneira, 2000 .

Santaella, L. (2004). O método anticartesiano de C. S. Peirce. São Paulo: Unesp, 2004. 
Santaella, L. (2005). Matrizes da linguagem e pensamento: sonoro, visual, verbal; aplicações na hipermídia. São Paulo: lluminuras; FAPESP, 2005.

Silveira, L. F. B. (2007). Curso de semiótica geral. São Paulo: Quartier Latin, 2007.

Silveira, L. F. B. (1985). Cosmos evolutivo e plano da criação na filosofia peirceana. // Trans/ Form/ Ação. 8, 1985. 1-24.

Thellefsen, T. L. (2003). Pragmaticism and the role of terminology. // Impact: an electronic journal on formalisation in text, media and language. apr. 2003. <http://www.impact.hum.auc.dk>. (2007-05-05).

Thellefsen, T. L. (2002). Semiotic knowledge organization: theory and method development. // Semiotica. 142:1/4 (2002) 71-90.

Thellefsen, T. L. ; Thellefsen, M. M. (2004). Pragmatic semiotics and knowledge organization. // Knowledge Organization. 31:3 (2004) 177-187.

Thellefsen, T. L. (2004). Knowledge profiling: the basis for knowledge organization. // Library Trends. 52:3 (winter 2004) 507-514.

Recibido: 2010-04-19. Revisado: 2010-07-01. Aceptado: 2010-07-06. 